\title{
TGF- $\beta 1$ induces epithelial-to-mesenchymal transition in chronic rhinosinusitis with nasal polyps through microRNA-182
}

\author{
Wenxiu Jiang, ${ }^{1}$ Chun Zhou, ${ }^{1}$ Chengxin $\mathrm{Ma},{ }^{2}$ Yujie Cao, ${ }^{1}$ Guohong Hu, ${ }^{2}$ Huabin $\mathrm{Li}^{1}$
}

\begin{abstract}
Background: Epithelial-to-mesenchymal transition (EMT) in nasal epithelial cells is involved in tissue remodeling of chronic rhinosinusitis with nasal polyps (CRSwNP). Our study investigated the molecular mechanisms that microRNA-182 (miR-182) regulated EMT in eosinophilic (Eos) and non-eosinophilic (non-Eos) CRSwNP.
\end{abstract}

Objective: To investigate the mechanism by which miR-182 regulates EMT in human nasal epithelial cells (hNEPCs).

Methods: The expression of EMT markers (E-cadherin, N-cadherin and vimentin), transforming growth factor (TGF)- $\beta 1$, and miR-182 were determined by western blotting and reverse transcription-quantitative PCR (RT-qPCR). Fluorescence in situ hybridization (FISH) was used to detect the miR-182 localization. Additionally, EMT markers expression and cell morphology changes were checked upon treatment with TGF- $\beta 1$, or TGF- $\beta 1$ with miR-182 inhibitor, or miR-182 mimics, or miR-182 inhibitor alone in hNEPCs.

Results: In both Eos CRSwNP and non-Eos CRSwNP, the expression levels of E-cadherin were downregulated while the expression levels of $\mathrm{N}$-cadherin, vimentin, TGF- $\beta 1$ and miR-182 were significantly upregulated compared with control nasal tissues. Additionally, more significant changes in these EMT markers were observed in the Eos-CRSwNP when compared with the non-Eos CRSwNP. Invitro hNEPCs model, TGF- $\beta 1$ upregulated miR-182 expression and promoted EMT in hNEPCs, indicated by changes in cell morphology and EMT markers expression. Furthermore, these upregulations were reversed by miR-182 inhibitor.

Conclusion: This study showed that miR-182-induced EMT in response to TGF- $\beta 1$ might promote nasal polypogenesis in both Eos CRSwNP and non-Eos CRSwNP, thus providing potential targets for the future development of novel therapeutic approaches for the management of CRSwNP.

Key words: Eosinophilic/non-Eosinophilic chronic rhinosinusitis, nasal polyps, MicroRNA-182, Epithelial-mesenchymal transition, Transforming growth factor (TGF)- $\beta 1$

\section{Affiliations:}

${ }^{1}$ Allergy Center, Department of Otolaryngology,

Eye \& ENT Hospital, Fudan University, Shanghai, China

2 The Key Laboratory of Stem Cell Biology,

Institute of Health Sciences, Shanghai Institutes for Biological

Sciences, Chinese Academy of Sciences \& Shanghai Jiao Tong

University School of Medicine, University of Chinese Academy of

Sciences, Shanghai, China

Corresponding author:

1. Huabin $\mathrm{Li}$

Allergy Center, Department of Otolaryngology,

Eye \& ENT Hospital, Fudan University

No. 83, Fenyang Road, Xuhui District, Shanghai, 200031, China

E-mail: allergyli@163.com

\section{Guohong $\mathrm{Hu}$}

The Key Laboratory of Stem Cell Biology, Institute of Health Sciences, Shanghai Institutes for Biological Sciences, Chinese Academy of Sciences \& Shanghai Jiao Tong University School of Medicine, University of Chinese Academy of Sciences 320 Yueyang Road, Xuhui District, Shanghai 200031, China E-mail: ghhu@sibs.ac.cn

\section{Introduction}

Chronic rhinosinusitis (CRS) is a heterogeneous group of sinus diseases in which the sinonasal mucosa is abnormally and persistently inflamed. ${ }^{1,2}$ CRS is currently divided into two types: CRS without nasal polyps (CRSsNP) and CRS with nasal polyps (CRSwNP) with distinctive expression of inflammatory 
and remodeling mediators. ${ }^{3}$ Through the immunohistological method, CRSwNP can be classified into the following 2 distinct subtypes based on observed eosinophil infiltration: eosinophilic CRSwNP (Eos CRSwNP) and non-eosinophilic CRSwNP (non-Eos CRSwNP). ${ }^{4}$

Eosinophilic inflammation has been considered as a major pathologic hallmark of CRSwNP. It has been found in 65-90\% and $50 \%$ of total CRSwNP cases in Caucasian and Chinese individuals, respectively. ${ }^{2,5}$ Compared with non-eosinophilic CRSwNP, eosinophilic CRSwNP demonstrates a higher degree of disease severity and a poorer response to surgery, which represents a hard-to-treat subtype of CRSwNP. However, the mechanisms underlying polypogenesis in patients with CRSwNP are still unclear.

Epithelial-to-mesenchymal transition (EMT) is a cellular process whereby epithelial cells acquire mesenchymal properties and lose cell-to-cell interactions and apicobasal polarity. ${ }^{6}$ Recently, it has been demonstrated that EMT and its effects on nasal epithelial cells may result in the tissue remodeling of nasal polyps. ${ }^{7,8}$ In patients with CRSwNP, especially those who have eosinophilic infiltration, may induce EMT, and a subsequent persistent EMT process may accelerate NP formation. ${ }^{9}$ Besides, loss of the epithelial marker protein, E-cadherin, is a fundamental event in EMT; this phenomenon has been observed in NP tissues. ${ }^{10}$ During EMT, E-cadherin is down-regulated while the mesenchymal markers $\mathrm{N}$-cadherin is up-regulated, resulting in weak cell-to-cell contacts and increased motility. ${ }^{11,12}$ Transforming growth factor (TGF)- $\beta 1$ via Smad3 signaling pathway is also involved in EMT. ${ }^{13}$ In previous studies on lower airway diseases such as asthma or COPD, TGF- $\beta 1$ and Smad3 were known to induce EMT in bronchial mucosa. ${ }^{13,14}$ In primary human nasal epithelial cells, TGF- $\beta 1$ was reported to promote EMT via upregulation of $\alpha$-smooth muscle actin ( $\alpha$-SMA). ${ }^{15}$

MicroRNAs (miRNAs) are single-strand and non-coding RNAs that regulate related gene expression by binding to the 3 '-untranslated regions (3'-UTR) of mRNA targets and induce mRNA destruction or translation inhibition. ${ }^{16}$ A previous study revealed that miRNAs may serve a vital role in the progression of inflammation and CRSwNP remodeling. ${ }^{17}$ miR-182 upregulation and TGF- $\beta 1$ overexpression accelerate EMT and promote cell migration and invasion in gallbladder cancer. ${ }^{18}$ Furthermore, miR-182 expression is upregulated in colorectal cancer, which significantly promotes epithelial-mesenchymal transition (EMT), cell proliferation, invasion and migration by targeting Special AT-rich Sequence-Binding protein $2 .{ }^{19}$ In allergic rhinitis, miR-182-5p inhibited the activation of the NF- $\mathrm{KB}$ signaling pathway by targeting TLR4. ${ }^{20}$ However, the regulation of EMT by miRNA-182 in CRSwNP metastasis is not far more understood.

In this study, we hypothesized that TGF- $\beta 1$-induced EMT and remodeling of nasal mucosa in CRSwNP is through miR-182. According to this assumption, expression of EMT markers, miR-182, and TGF- $\beta 1$ was verified in nasal polyps of CRSwNP patients and inferior turbinates of controls. Additionally, by using the hNEPCs model, we sought to investigate the effect TGF- $\beta$ in mediating miR-182 on EMT during polyp formation and the molecular mechanisms of tissue remodeling in CRSwNP development.

\section{Materials and Methods Subjects}

Sinonasal mucosa specimens from 26 patients with Eos CRSwNP, 23 patients with non-Eos CRSwNP and 15 control patients were obtained from the Department of Otolaryngology, Eye and Ear, Nose, and Throat Hospital, Fudan University. Inferior turbinates (IT) from patients with anatomical variations but without sinus disease undergoing septoplasty or rhinoseptoplasty were collected as controls. For CRSwNP, polyp tissue samples in the middle meatus area were used. The diagnosis of sinus disease was carried out according to a European Position Paper on Rhinosinusitis and Nasal Polyps (EPOS), ${ }^{1}$ which is based on history, clinical examination, nasal endoscopy, and sinus computed tomography (CT) scans. Patients who had a previous history of acute infection, fungal sinusitis, cystic fibrosis, antrochoanal polyps, or gastroesophageal reflux disease were excluded from the study based on the EPOS definition. None of the subjects received antihistamines, antileukotrienes, oral or intranasal decongestants, or intranasal anticholinergics during the 2 weeks before surgery. None of the subjects used oral and topical application of corticosteroids and antibiotics at least 4 weeks prior to surgery. Females who were pregnant or breastfeeding were also excluded from the study. The demographic data of all subjects enrolled in this study are listed in Table $\mathbf{1}$.

Table 1. Demographic and clinical characteristics of subjects

\begin{tabular}{lccc} 
& Controls & $\begin{array}{c}\text { Eos } \\
\text { CRSwNP }\end{array}$ & $\begin{array}{c}\text { Non-Eos } \\
\text { CRSwNP }\end{array}$ \\
\hline Patients, (no.) & 15 & 26 & 23 \\
\hline Gender (M/F) & $10 / 5$ & $19 / 7$ & $14 / 9$ \\
\hline Age (y) & $39 \pm 11$ & $47 \pm 16$ & $45 \pm 14$ \\
\hline SPT (positive/negative) & $1 / 14$ & $6 / 20$ & $5 / 18$ \\
Asthma (no.) & 1 & 2 & 2 \\
\hline Smoking history (yes/no) & $0 / 15$ & $2 / 24$ & $1 / 22$ \\
\hline $\begin{array}{l}\text { Endoscopic } \\
\text { (Lund-Kennedy) scores }\end{array}$ & N/A & $7.0 \pm 2.1$ & $6.7 \pm 2.1$ \\
\hline CT (Lund-Mackay) scores & N/A & $12.7 \pm 5.2$ & $12.2 \pm 5.4$ \\
\hline
\end{tabular}

Age, Endoscopic score and CT score are presented as mean \pm SD. SPT $=$ skin-prick test; $\mathrm{CT}=$ computed tomography; Eos CRSwNP $=$ eosinophilic chronic rhinosinusitis with nasal polyps; Non-Eos CRSwNP = non-eosinophilic chronic rhinosinusitis with nasal polyps; M, male; F, female.

This study was approved by the ethics committee boards at the Department of Otolaryngology, Eye and Ear, Nose, and Throat Hospital, Fudan University. All study participants were enrolled after providing written informed consent. According to eosinophil levels, the CRSwNP patient population was divided into Eos CRSwNP and non-Eos CRSwNP. In summary, the cutoff value separating Eos CRSwNP from non-Eos CRSwNP was set at 8 eosinophils/high-power field (HPF); a polyp with $\geq 8$ eosinophils/HPF was defined as Eos CRSwNP. All the laboratory assays were performed in a single-blinded manner. 
Each specimen was divided into 3 pieces for further analysis. The first piece was stored immediately in RNAlater solution (Tiangen, Beijing, China) for subsequent RNA extraction; the second was fixed with $4 \%$ paraformaldehyde and then embedded in paraffin wax for immunohistochemical (IHC) staining, and the third was stored immediately at $-80^{\circ} \mathrm{C}$ for western blot analysis.

\section{qRT-PCR Assay}

The mRNA expression levels of target genes were detected by RT-qPCR analysis as previously described. ${ }^{21}$ Briefly, total RNA was extracted with TRIzol reagent (Invitrogen, Carlsbad, CA), according to the manufacturer's instructions. Reverse transcription was performed, in which cDNA for quantitative PCR was synthesized from $2 \mu \mathrm{g}$ of total RNA using an oligo (dT) 18 primer and M-MLV reverse transcriptase (Takara, Dalian, China). RNA integrity and the success of the reverse transcription reaction were monitored by PCR amplification of Glyceraldehyde 3-phosphate dehydrogenase (GAPDH) transcripts. Expression of mRNA was determined using the ABIPRISM7500 Detection System (Applied Biosystems, Foster City, CA) and SYBRP remix Ex Taq II kit (Takara). The primers sequences were as follows: E-cadherin forward (5'-TCACTGACACCAACGATAATCC-3') and reverse (5'-TTTCAGTGTGGTGATTACGACGTTA-3'), N-cadherin forward (5'-CCATCAAGCCTGTGGGAATC-3') and reverse (5'-GCAGATCGGACCGGATACTG-3'), Vimentin forward (5'-CCGAAAACACCCTGCAATCTTTC- $3^{\prime}$ ) and reverse (5'-CACATCGATTTGGACATGCTGT-3'), GAPDH forward (5'-ACCCAGAAGACTGTGGATGG-3') and reverse (5'-TTCTAGACGGCAGGTCAGGT-3'), TGF- $\beta 1$ forward (5'-GGCCAGATCCTGTCCAAGC-3') and reverse (5'-GTGGGTTTCCACCATTAGCAC-3'). The mean cycle threshold $(\mathrm{Ct})$ values were normalized to those of GADPH, and the relative mRNA levels of the target genes were analyzed using the $2^{-\Delta \Delta \mathrm{Ct}}$ method.

\section{Western blotting analysis}

The protein level of E-cadherin, $\mathrm{N}$-cadherin and vimentin were determined by western blotting analysis. Briefly, Total proteins from hNEPCs and the tissues were dissected on ice and homogenized by sonication in radioimmunoprecipitation assay lysis buffer containing a protease inhibitor cocktail (Sigma-Aldrich, St. Louis, MO). The protein concentration in the supernatants was determined using the BCA method. Samples containing $15 \mu \mathrm{g}$ of protein were boiled, subjected to SDS-PAGE in 10\% Tris-glycine gels, and electrophoretically transferred to a polyvinylidene fluoride membrane. The membrane was blocked with 5\% fat-free milk in Tris-buffered solution containing $0.05 \%$ Tween-20 for 1 hour at room temperature before being incubated with primary antibodies against E-cadherin, N-cadherin, vimentin at a dilution of 1:2,000 (Abcam, Cambridge, MA) overnight at $4^{\circ} \mathrm{C}$. The membrane was then incubated with horseradish peroxidase-linked secondary antibody for $1 \mathrm{~h}$ at room temperature. The relative band density of the target protein relative to the $\beta$-actin protein was determined with Bio-Rad Quantity One 1-D Analysis Software (Bio-Rad Laboratories, Hercules, Calif). The relative intensities of each protein signal were obtained by dividing the intensities of each protein signal by the intensities of housekeeping gene $\beta$-actin signals.

\section{Fluorescence in situ hybridization (FISH) and total fluores- cence intensity evaluation}

The dried slides were then successively soaked in $70 \%$, $85 \%$, and $100 \%$ ethanol for $1 \mathrm{~min}$ and then air dried for 10 min. The tissue sections on the slide were treated with $4 \mu \mathrm{L}$ mR-182-5p probe solution (5'-fam-AGTGTGAGTTCTACCATTGCCAAA-fam-3') with a dilution of 1:600, and then coverslips were applied. Afterward, the probe was hybridized overnight at room temperature in the dark. The next day, coverslips were removed, and the slides were washed in SSC buffer at room temperature. Then, the cell area was dyed with DAPI solution. Images of miR182 on tissue sections were captured at $\times 400$ magnification with a fluorescence microscope (Olympus IX51, Tokyo, Japan). Total fluorescence intensity (TFI) measurements were performed by multiplying the positive area by mean fluorescence intensity, and corrected by subtracting the background auto-fluorescence.

\section{Cell culture and treatment}

Primary human nasal epithelial cells (hNEPCs) were obtained from Shanghai Institutes for Biological Sciences. Cells were grown in a Dulbecco's modified eagle medium (Gibco; Thermo Fisher Scientific, Inc.) supplemented with 10\% FS (Invitrogen; Thermo Fisher Scientific, Inc.) in a humidified incubator at $37^{\circ} \mathrm{C}$ with $5 \% \mathrm{CO}_{2}$. Cells were seeded in $21 \mathrm{~cm}^{2}$ culture flasks and grown in complete medium to a density of 60-70\%. Lipofectamine 2000 (2.5 $\mu \mathrm{L}$; Invitrogen Company, USA) was diluted with $250 \mu \mathrm{L}$ serum-free culture medium and then kept at room temperature for $5 \mathrm{~min}$. Both dilutions were gently mixed and stored at room temperature for $15 \mathrm{~min}$ for complex formation, and serum-free culture medium was used to wash cells. Serum-free culture medium was added to the complex, and then the complex was transferred to culture flasks for transfection at $37^{\circ} \mathrm{C}$ in $5 \% \mathrm{CO}_{2}$.

hNEPCs were cultured in a $6 \mathrm{~cm}$ plate for $24 \mathrm{~h}$. The primers used to amplify EMT were designed based on the published sequence: miR-182 inhibitor sense (5'-AGUGUGAGUUCUACCAUUGCCAA- $3^{\prime}$ ) and negative control sense (5'-CAGUACUUUUGUGUAGUACAA- $3^{\prime}$ ) with a dilution of 1:400, miR-182 mimics sense (5'-UUUGGCAAUGGUAGAACUCACACU- $3^{\prime}$ ), antisense (5'-UGUGAGUUCUACCAUUGCCAAAUU- $3^{\prime}$ ) and miR-182 mimics negative control sense (5'-UUCUCCGAACGUGUCACGUTT-3'), antisense (5'-ACGUGACACGUUCGGAGAATT-3') with a dilution of 1:400. Cells at $60-70 \%$ were transfected with miR-182 inhibitor, miR182 mimics, miR-182 mimics negative control, and miR-182 inhibitor negative control by using lipofectamine 2000 transfection reagent, respectively. The cells were harvested at $24 \mathrm{~h}$ post-transfection for subsequent studies.

To explore the effect of TGF- $\beta 1$ on hNEPCs morphology and EMT. hNEPCs were stimulated with $5 \mathrm{ng} / \mathrm{ml}$ TGF- $\beta 1$ (CST, Inc.) in the presence of miR-182 inhibitor or inhibitor control incubated with the cells for $48 \mathrm{~h}$ at $37^{\circ} \mathrm{C}$. hNEPC morphology was observed under a DM500 light microscope (Leica Microsystems, Inc.). 


\section{Immunohistochemistry staining}

Paraffin-embedded human nasal tissues were cut into $4-\mu \mathrm{m}$ sections and placed onto glass slides, and IHC staining was performed by the peroxidase-labeled streptavidin biotin technique. The sections were incubated overnight at $4^{\circ} \mathrm{C}$ with primary antibodies against E-cadherin, N-cadherin and Vimentin with a dilution of 1:200, 1:250 and 1:200 (Signaling Technology, Inc. MA). Subsequently, each section was incubated with a secondary antibody and then with horseradish peroxidase-labeled streptavidin complex (Santa Cruz Biotechnology, USA). The distribution of peroxidase was revealed by incubating the sections in a solution containing 3\% 3, 3-diaminobenzidine tetrahydrochloride before being counterstained with hematoxylin and coverslipped. The negative IHC control procedure was performed by replacing the primary antibodies with normal IgG in appropriate concentrations. The sections were blindly examined and coded with no awareness of the clinical data with an Olympus CX40 Microscope (Olympus Optical Co, Hamburg, Germany). The number of positive cells (brown cells) was counted in 10 randomly HPFs and averaged.

\section{Statistical Analysis}

At least 3 independent experiments provided the results in this study. The data were analyzed by SPSS 22.0 and GraphPad Prism software 8.0. Results are expressed as means \pm SD. Differences between the values were determined by Student-NewmanKeuls q test or analysis of variance (ANOVA). All statistical tests were 2-sided, and significance was considered when the $p$-value was less than 0.05 .

\section{Results \\ EMT markers expression in sinonasal tissues}

To determine whether EMT occurs in CRSwNP patients, we firstly evaluated the expression of EMT markers (N-cadherin, E-cadherin, and vimentin) in nasal polyps from patients with Eos CRSwNP and non-Eos CRSwNP and inferior turbinate from controls. The $\mathrm{qPCR}$ revealed E-cadherin mRNA expression significantly decreased in Eos CRSwNP and non-Eos CRSwNP compared with controls $(P<0.01 ; P$ $=0.0068$ respectively; Figure 1a). Additionally, the expression levels of E-cadherin mRNA in Eos CRSwNP were much lower than in non-Eos CRSwNP patients $(P<0.001$; Figure 1a). On the contrary, N-cadherin and Vimentin mRNA were significantly increased in nasal polyps from Eos CRSwNP and nonEos CRSwNP compared with controls (both $P<0.001$, Figure $\mathbf{1 b}$ and $\mathbf{1 c})$. The expression levels of $\mathrm{N}$-cadherin and vimentin mRNA in Eos CRSwNP were significantly higher than in non-Eos CRSwNP $(P<0.05, P<0.001$ respectively, Figure $\mathbf{1 b}$ and $\mathbf{1 c})$. Next, we examined the protein and localization of EMT markers with IHC staining. We found E-cadherin was significantly reduced in Eos CRSwNP and non-Eos CRSwNP compared to controls (both $P<0.05$, Figure 1d). N-cadherin and vimentin expressions were significantly higher in Eos CRSwNP and non-Eos CRSwNP compared to controls (both $P<0.05$, Figure 1d). As shown by IHC staining, we found that E-cadherin and N-cadherin immunoreactivity of sinonasal tissues was mainly localized in mucosal and glandular epithelia, whereas vimentin was detected exclusively in submucosal and perivascular areas. a

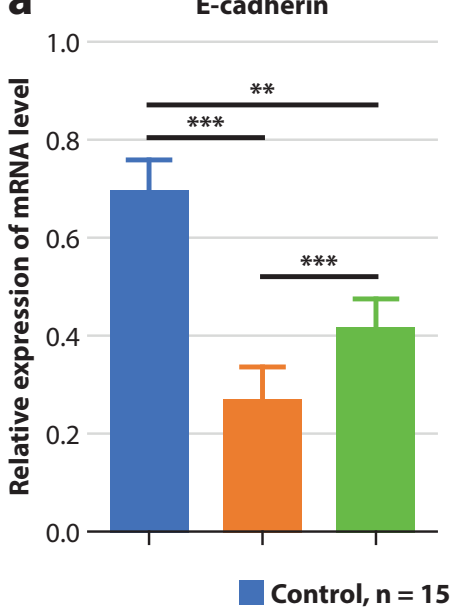

b
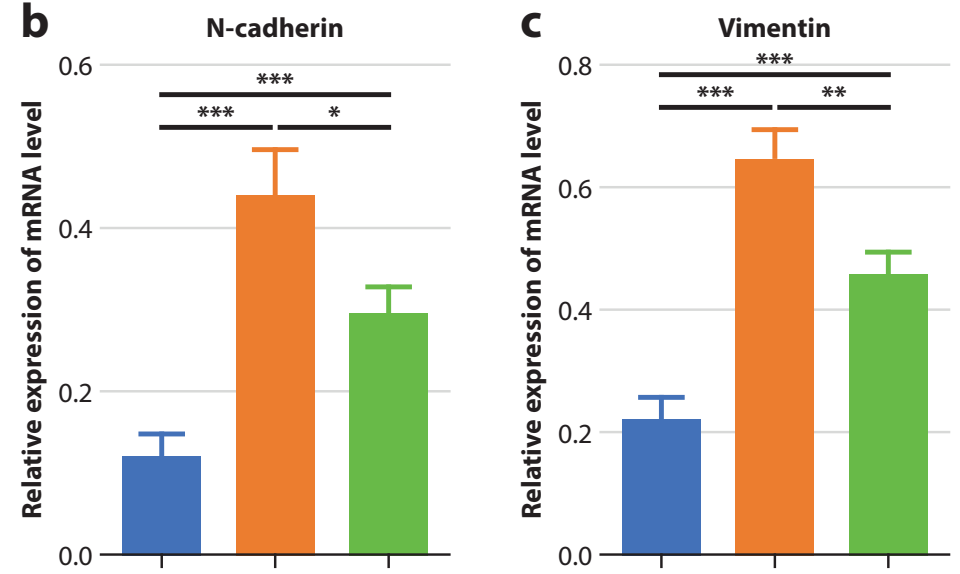

EOS CRSwNP, $\mathbf{n}=\mathbf{2 6}$

NON-EOS CRSwNP, $\mathrm{n}=\mathbf{2 3}$

Figure 1. The experession levels of E-cadherin, $\mathrm{N}$-cadherin and vimentin in controls, Eos CRSwNP and non-Eos CRSwNP.

(a) E-cadherin mRNA levels were decreased in polyp tissues from Eos CRSwNP and non-Eos CRSwNP compared with sinonasal tissues from controls. (b-c) N-cadherin and vimentin mRNA levels were increased in polyp tissues from Eos CRSwNP and nonEos CRSwNP compared with sinonasal tissues from controls. (d) Representative immunostaining results of E-cadherin, N-cadherin and vimentin in sinonasal mucosa of controls and Eos CRSwNP and non-Eos CRSwNP.

${ }^{\star} P<0.05,{ }^{\star \star} P<0.01,{ }^{* \star} P<0.001, \mathrm{NP}=$ nasal polyp; Eos CRSwNP = eosinophilic chronic rhinosinusitis with nasal polyps; nonEos CRSwNP = non-eosinophilic chronic rhinosinusitis with nasal polyps. All slides were viewed at $\times 200$ magnification. 
d
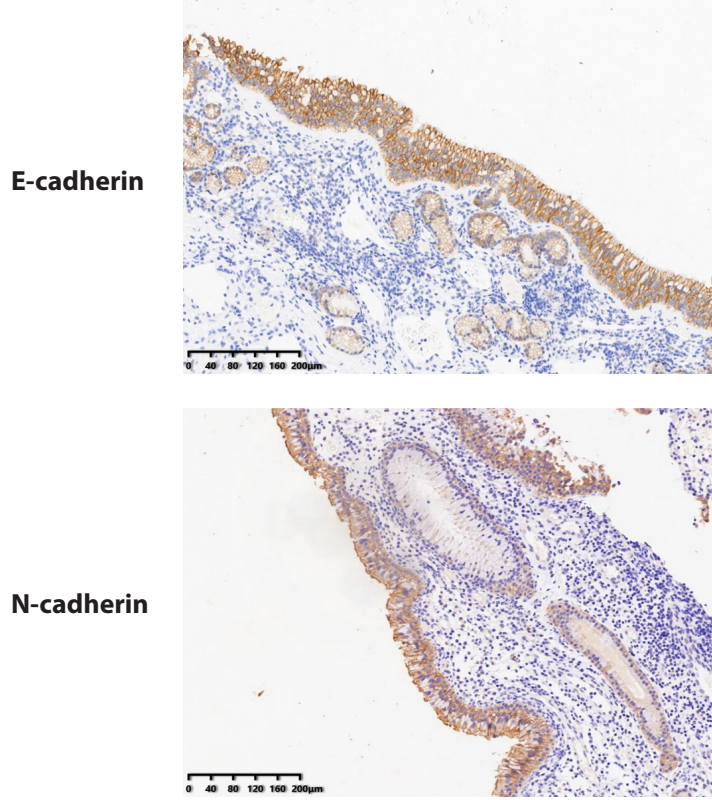

N-cadherin

Vimentin
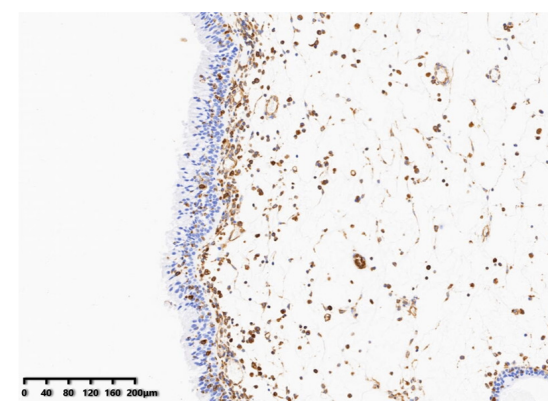

EOS CRSwNP
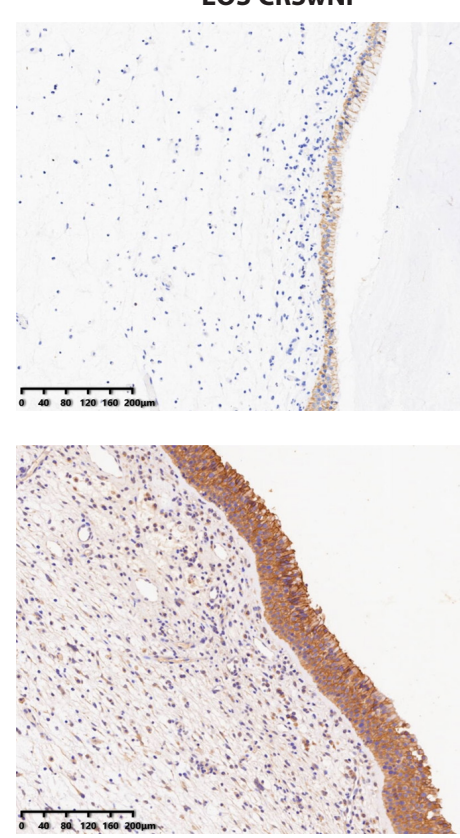
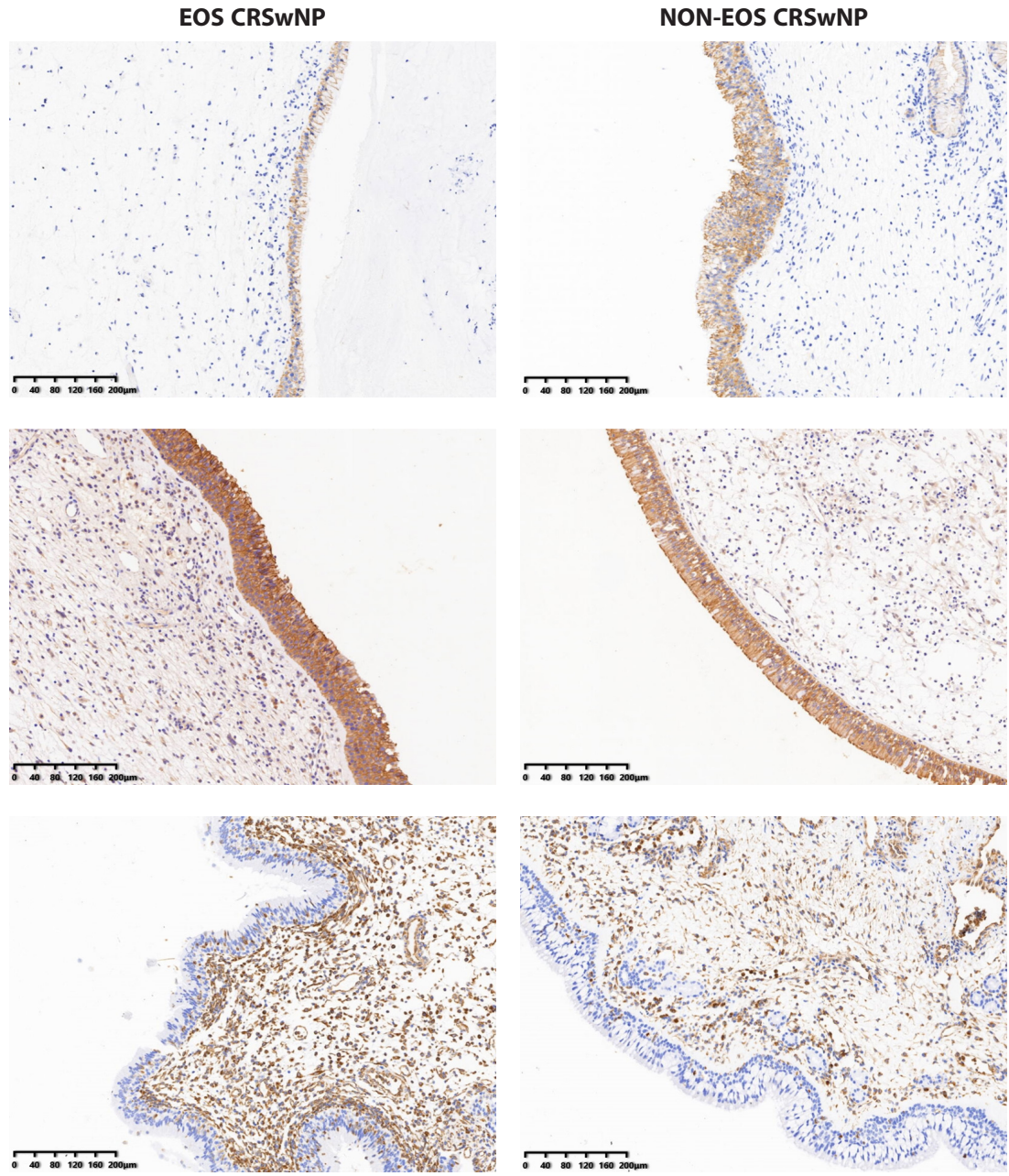
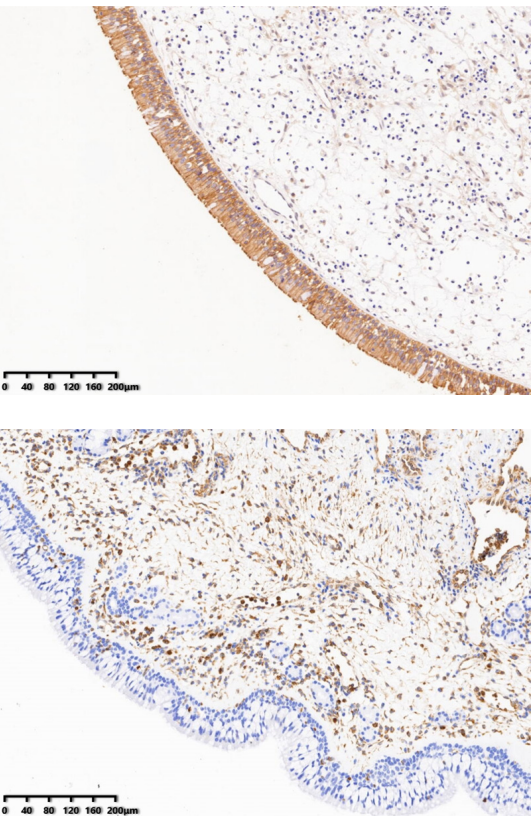

Figure 1. (Continued)

a

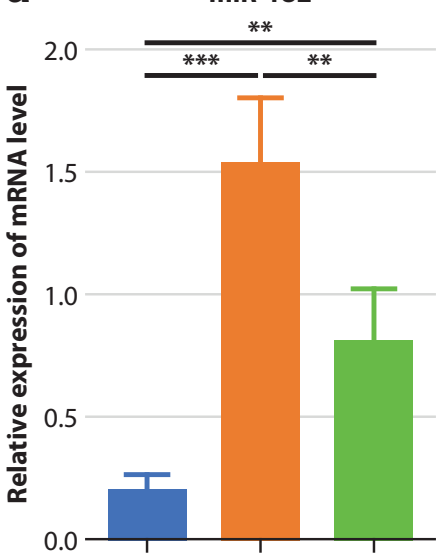

Control, $\mathbf{n}=15$ b

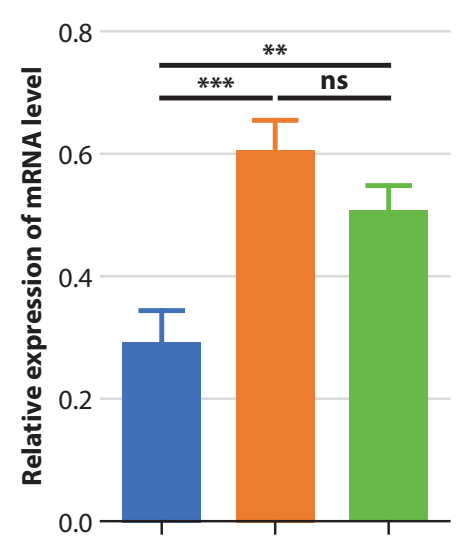

EOS CRSwNP, $\mathbf{n}=\mathbf{2 0}$
C

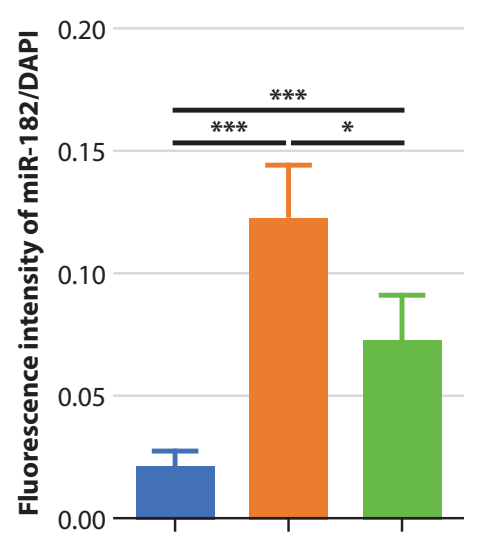

Figure 2. TGF- $\beta 1$ and miR-182 are upregulated in Eos CRSwNP and non-Eos CRSwNP.

The mRNA levels of miR-182 (a) and TGF- $\beta 1$ (b) levels were increased in Eos CRSwNP and non-Eos CRSwNP compared with controls. (c) Representative fluorescent image is shown with miR-182 (green) and nuclear DAPI (blue) $(\times 200$ magnification). (d) The TFI of miR-182 was significantly higher in Eos CRSwNP and non-Eos CRSwNP than in controls.

${ }^{\star} P<0.05,{ }^{* *} P<0.01,{ }^{* *} P<0.001$; TFI: total fluorescence intensity; DAPI: 4-6-Diamidino-2-phenylindole dihydrochloride; $\mathrm{NP}=$ nasal polyp; Eos CRSwNP = eosinophilic chronic rhinosinusitis with nasal polyps; non-Eos CRSwNP = non-eosinophilic chronic rhinosinusitis with nasal polyps. The relative mRNA expression versus the housekeeping genes encoding GAPDH is shown; All slides were viewed at $\times 200$ magnification. 
APJAI

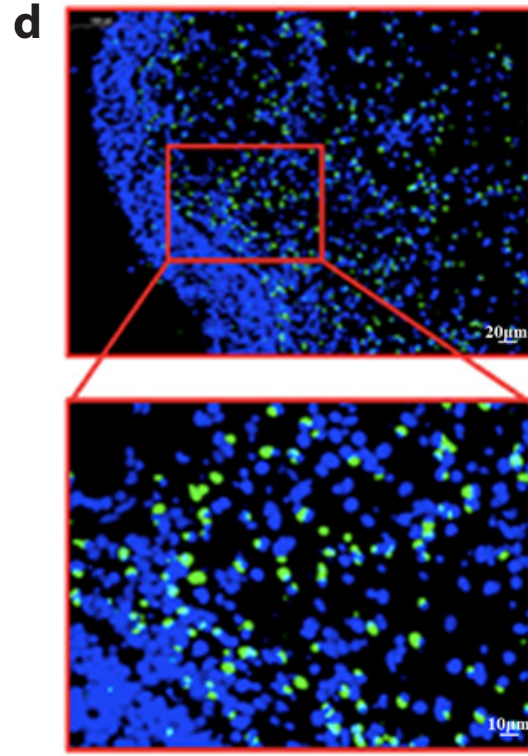

EOS CRSwNP

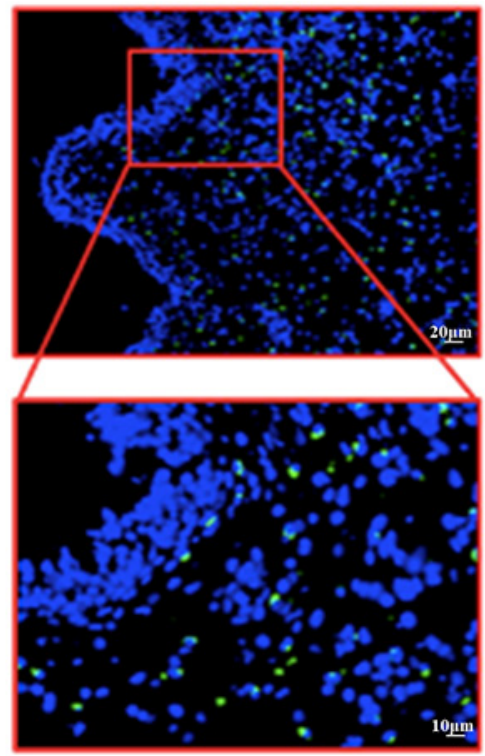

NON-EOS CRSWNP

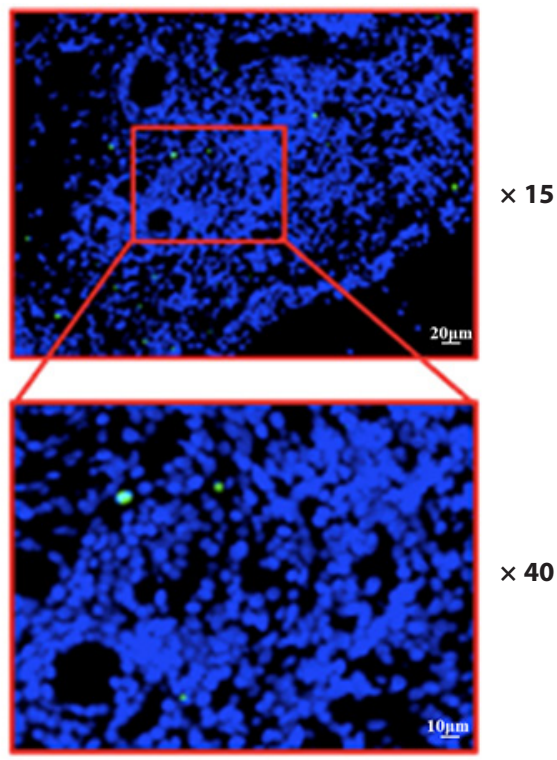

Control

Figure 2. (Continued)

\section{Increased expression of miR-182 and TGF- $\beta 1$ in sinonasal} tissues

Furthermore, we found that the mRNA expression levels of miR-182 and TGF- $\beta 1$ were significantly higher in both Eos CRSwNP and non-Eos CRSsNP than in controls (both $P$ $<0.01$, Figure 2a and 2b). However, Eos CRSwNP demonstrated significantly higher mRNA levels of miR-182 and TGF- $\beta 1$ compared with non-Eos CRSsNP (both $P<0.001$, Figure $2 \mathbf{a}$ and $\mathbf{2 b}$ ). To identify the cellular source of miR-182 in sinonasal mucosa, we performed FISH in sinonasal tissues and found that the fluorescence intensity of miR-182 was significantly increased in epithelium and submucosa of sinonasal mucosa from Eos CRSwNP and non-Eos CRSwNP compared with controls (Figure 2d). According to the semi-quantitative scoring system, we examined the levels of miR-182 in sinonasal mucosa and quantification of TFI showed miR-182 was significantly higher in Eos CRSwNP than control subjects (5.8-fold; $P<0.05$, Figure 2c) and non-Eos CRSwNP (1.9fold; $P<0.001$, Figure 2c).
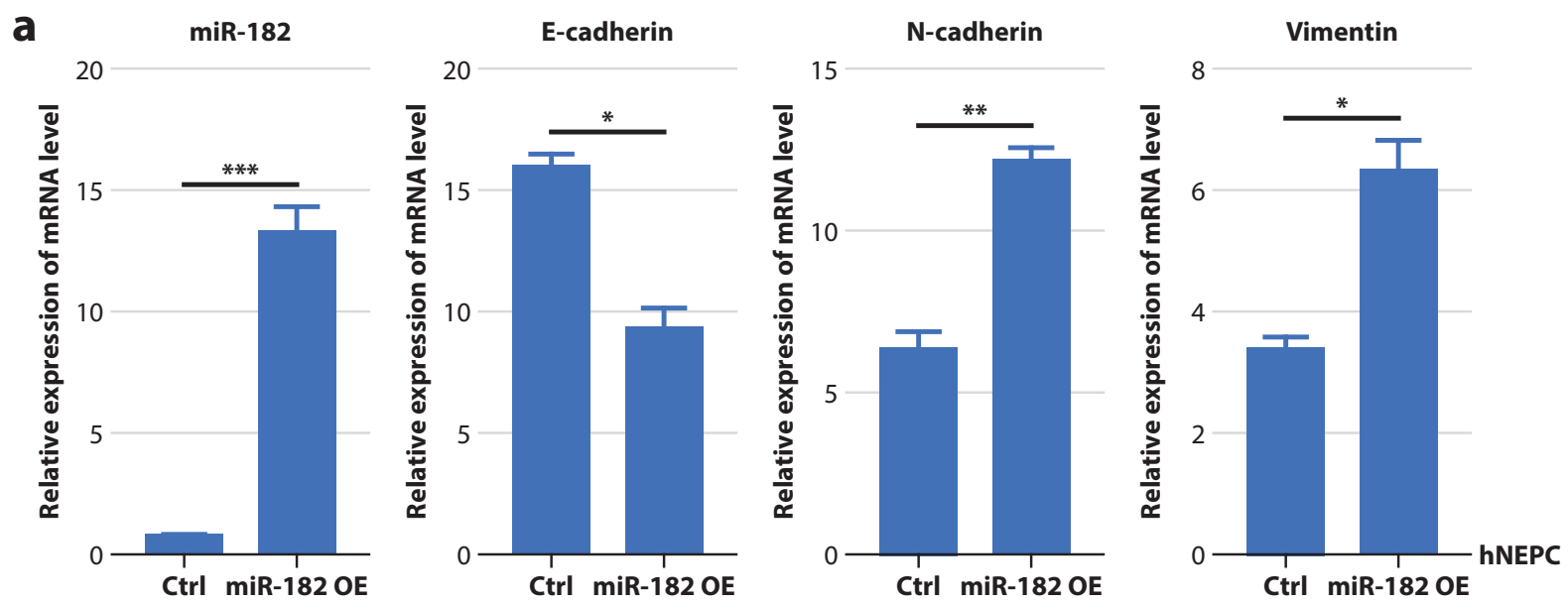

Figure 3. Overexpression of miR-182 resulted in EMT-like transformation in hNEPCs.

(a) The mRNA expression levels of miR-182, E-cadherin, N-cadherin and vimentin in hNEPCs. (b) The protein expression of E-cadherin, N-cadherin and vimentin in hNEPCs. (c) Quantitative analysis of E-cadherin, N-cadherin and vimentin protein levels in hNEPCs. (d) The morphological changes induced by miR-182 mimics compared with the control group by phase-contrast microscopy. ( $\times 200$ magnification)

OE: overexpression; ${ }^{*} p<0.05,{ }^{* *} p<0.01,{ }^{* *} p<0.001$. 
b

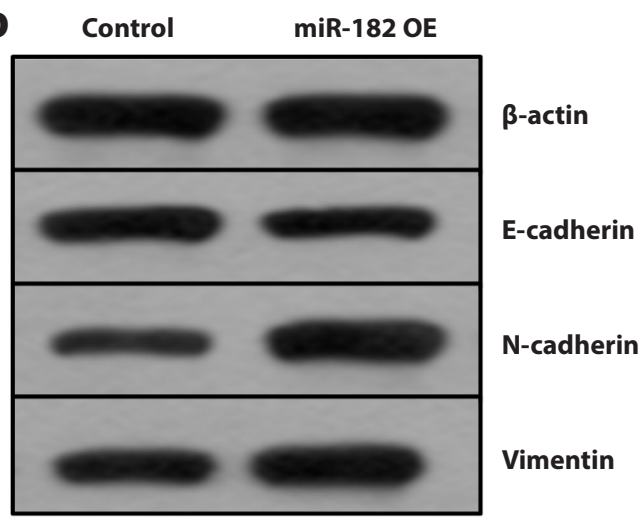

d

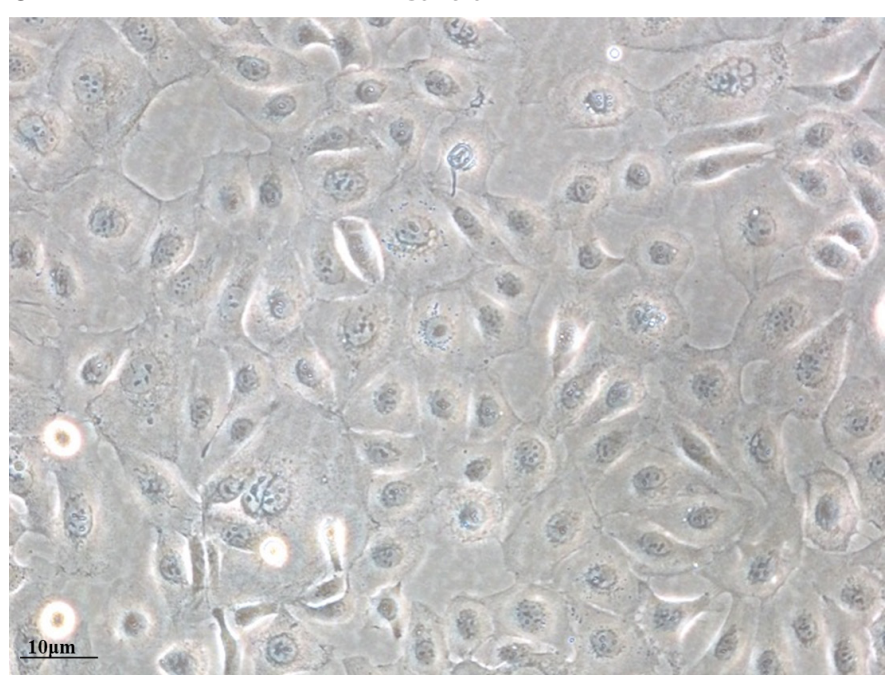

C

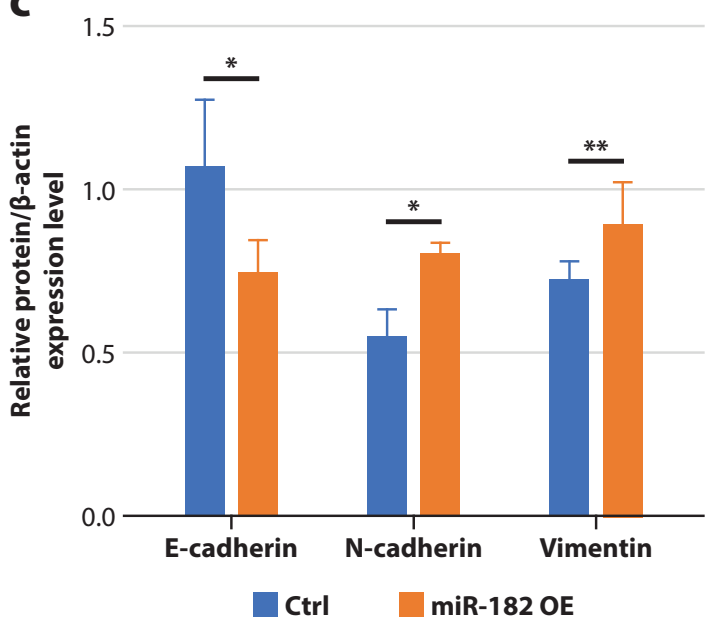

Ctrl miR-182 OE

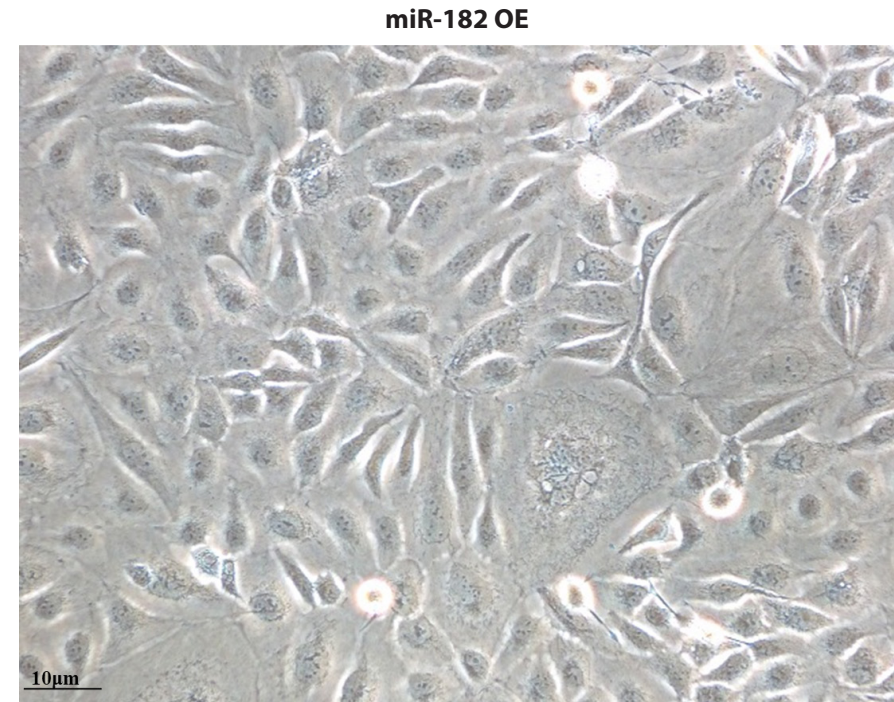

Figure 3. (Continued)

a

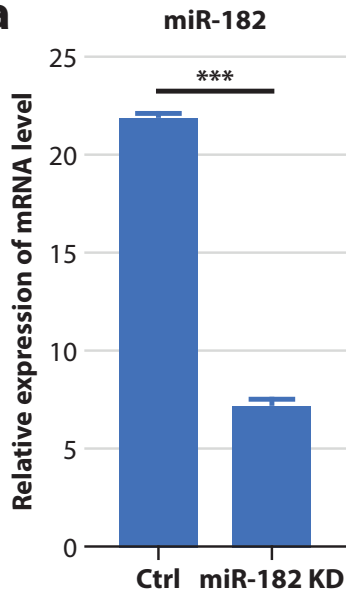

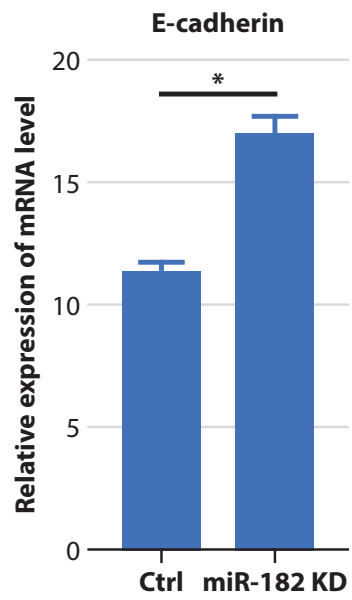
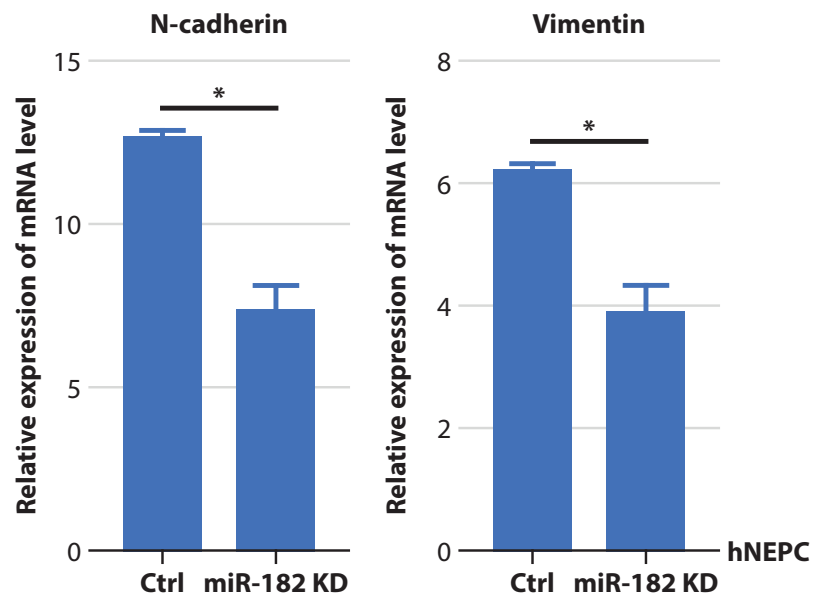

Figure 4. Downregulation of miR-182 inhibited EMT-like transformation in hNEPCs.

(a) The mRNA expression levels of miR-182 E-cadherin, N-cadherin and vimentin in hNPECs. (b) The protein expression of E-cadherin, N-cadherin and vimentin in hNPECs. (c) Quantitative analysis of E-cadherin, N-cadherin and vimentin protein levels in hNEPCs. (d) The morphological changes induced by miR-182 inhibitor compared with the control group by phase-contrast microscopy. ( $\times 200$ magnification)

KD: knockdown; ${ }^{\star} P<0.05,{ }^{\star *} P<0.01,{ }^{* *} P<0.001$. 

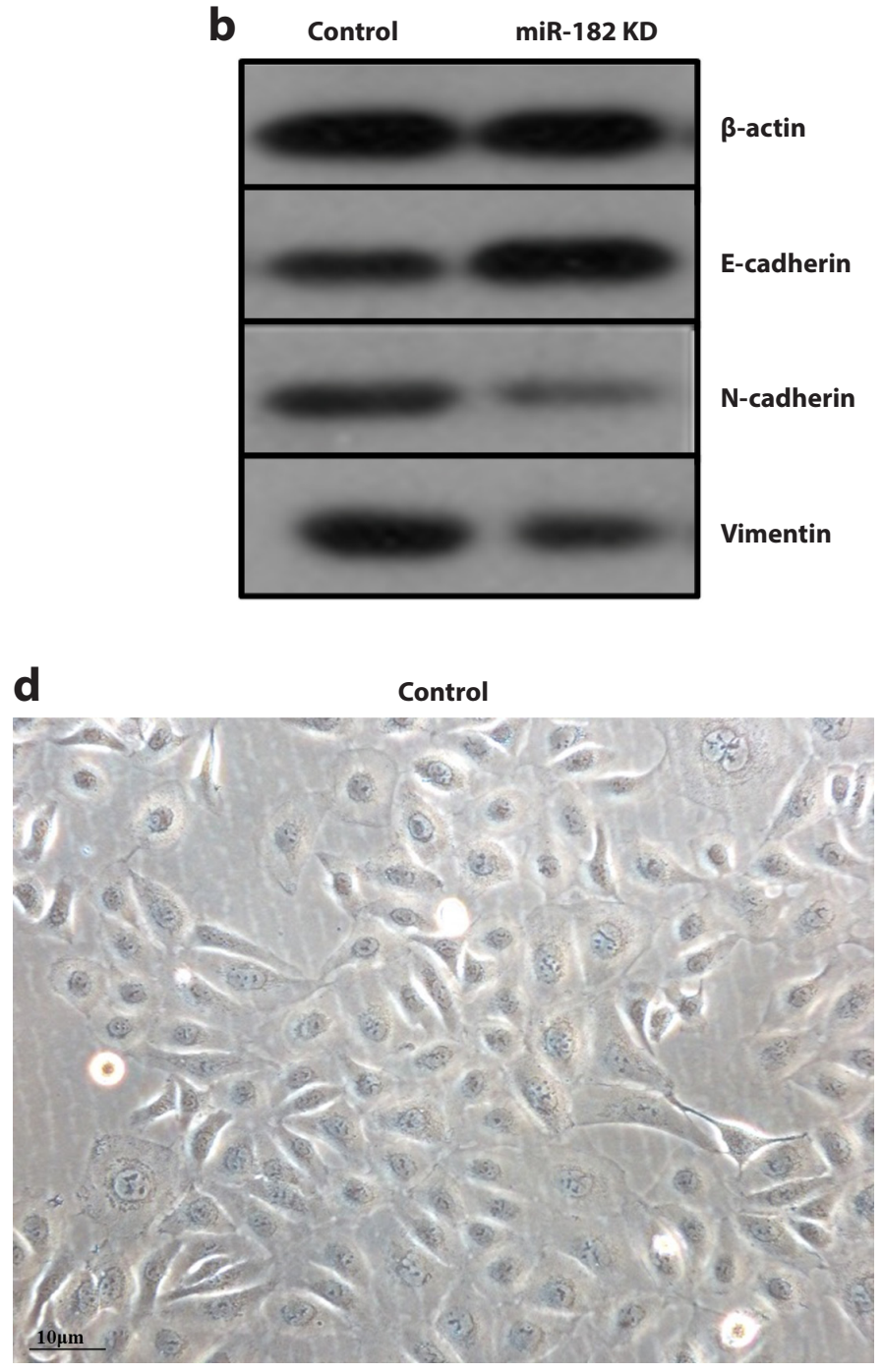

Figure 4. (Continued)

\section{miR-182 induced EMT in hNEPCs}

To determine the role of miR-182 in EMT, we then examined whether transfection with miR-182 mimics or inhibitors could attenuate EMT in hNEPCs. Consequently, the overexpression of miR-182 alone resulted in EMT-like transformation in hNEPCs. And transfection of miR-182 mimics into hNEPCs leads to reduced E-cadherin and increased N-cadherin and vimentin expression (Figure 3a-c). Furthermore, miR-182 mimics induced transition hNEPCs from normal epithelial morphology with cobblestone-like appearance into migratory mesenchymal morphology with an abnormally elongated appearance (Figure 3d). After downregulation of miR-182 expression in hNEPCs following transfection with the miR-182 inhibitor, we found EMT was inhibited significantly. As shown in our data, migratory mesenchymal morphological changes induced by miR-182 were ameliorated (Figure 4d). Moreover, we observed the recovery of E-cadherin expression and loss of $\mathrm{N}$-cadherin and vimentin expression by western blotting and qPCR after downregulation of miR182 expression (Figure 4a-c).
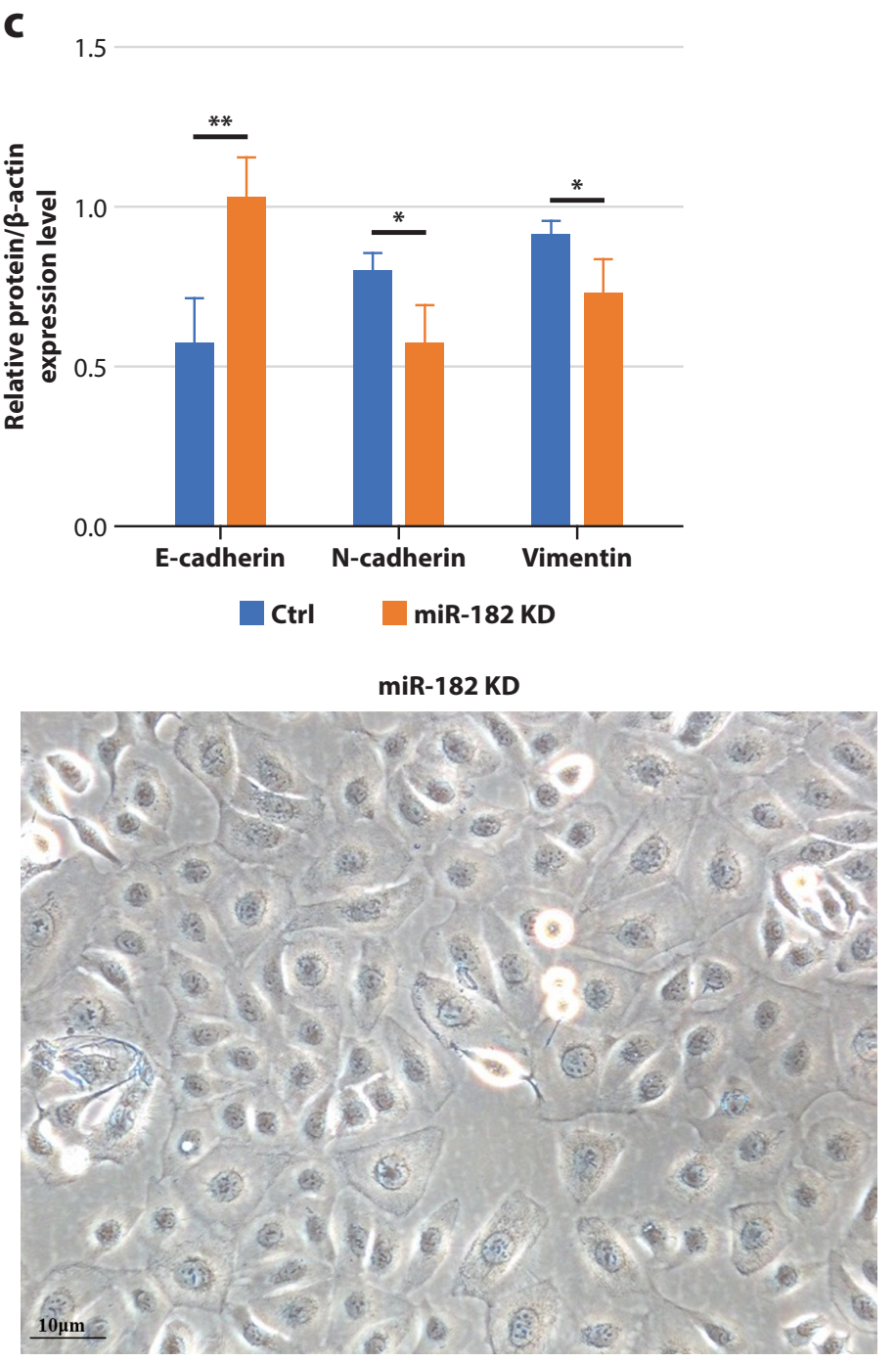

TGF- $\beta 1$ upregulates miR-182 expression and induces EMT in hNEPCs

A previous study confirmed that TGF- $\beta 1$ induces EMT in primary airway epithelial cells. ${ }^{14}$ Therefore, we then examined the expression changes of miR-182 and EMT markers in hNEPCs following TGF- $\beta 1$ treatment. We found that TGF- $\beta 1$ treatment significantly downregulated E-cadherin expression and upregulated miR-182, N-cadherin and vimentin expression in hNEPCs (Figure 5a-c). Phase-contrast microscopy revealed that treatment with TGF- $\beta 1$ changed hNEPCs from normal epithelial morphology with a cobblestone-like appearance into a migratory mesenchymal morphology with an abnormally elongated appearance (Figure 5d). However, these expression levels were reversed by miR-182 inhibitor. And transfection of miR-182 inhibitor into hNEPCs leads to reduced N-cadherin and vimentin and increased E-cadherin expression (Figure 6a-c), which means TGF- $\beta 1$ treatment could lead hNEPCs to undergo EMT-like transformation. 
a

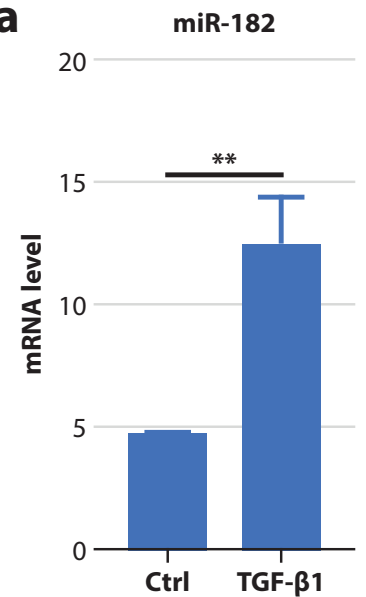

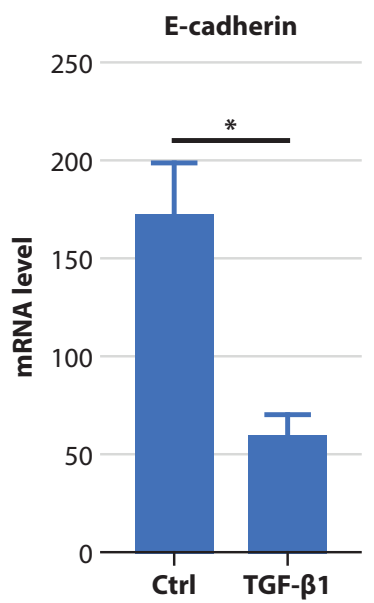

b

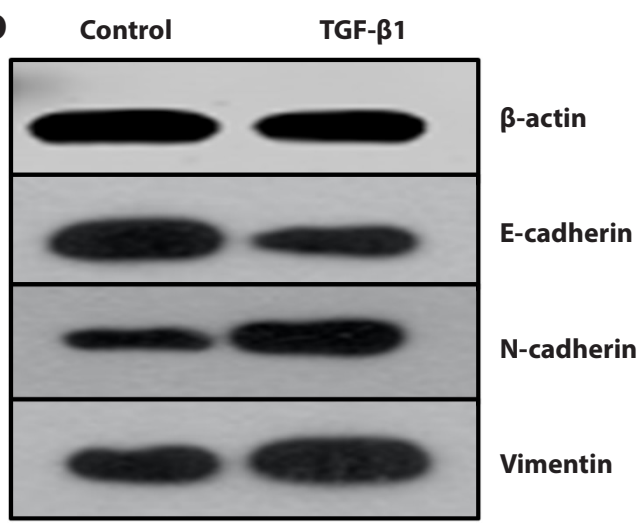

d

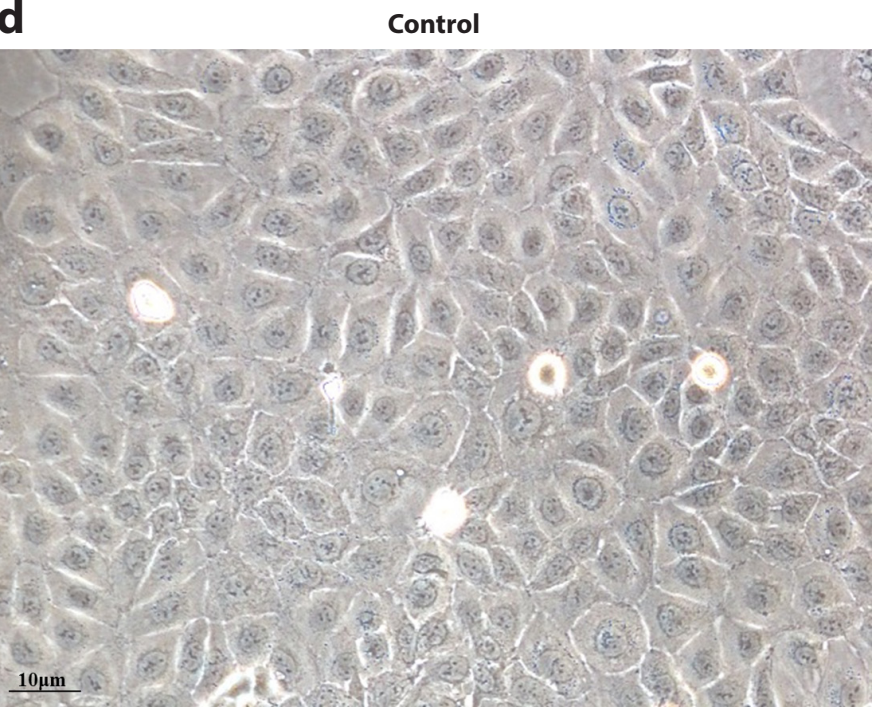

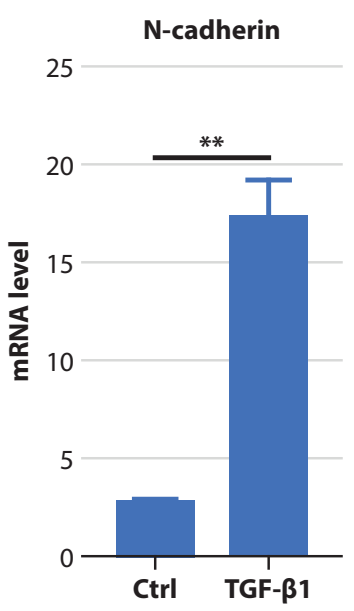

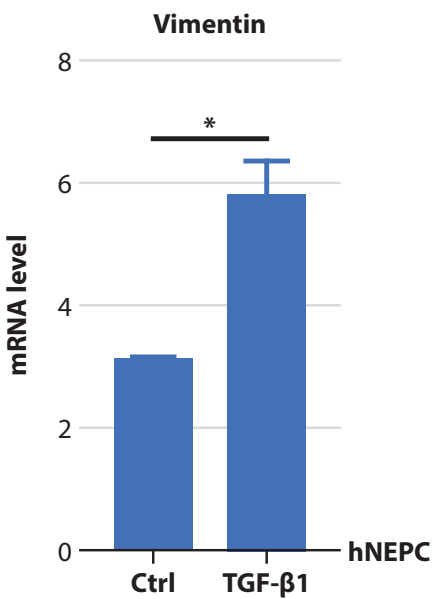

C
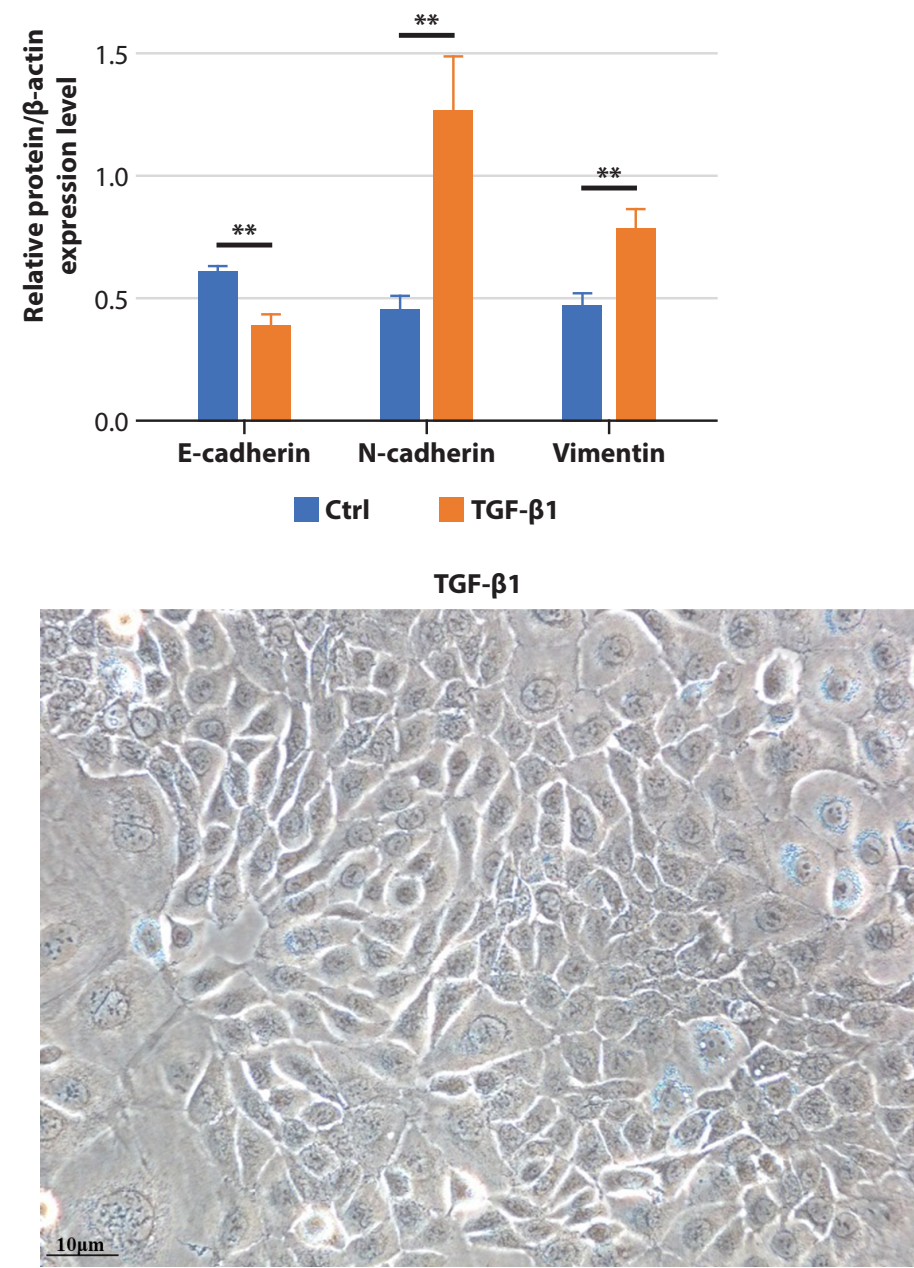

Figure 5. TGF- $\beta 1$ upregulated miR-182 and induced EMT in hNEPCs

(a) The mRNA expression levels miR-182, E-cadherin, N-cadherin and vimentin in hNEPCs were assessed by qPCR. (b) The protein expression levels of E-cadherin, N-cadherin and vimentin in hNEPCs were detected by western blotting. (c) Quantitative analysis of E-cadherin, N-cadherin and vimentin protein levels in hNEPCs. (d) Phase-contrast microscopy revealed that treatment with TGF- $\beta 1$ changed hNEPCs morphological appearance.

The morphological changes induced by TGF- $\beta 1$ compared with the control group by phase-contrast microscopy ( $\times 200$ magnification).

${ }^{\star} P<0.05,{ }^{*} P<0.01$, 

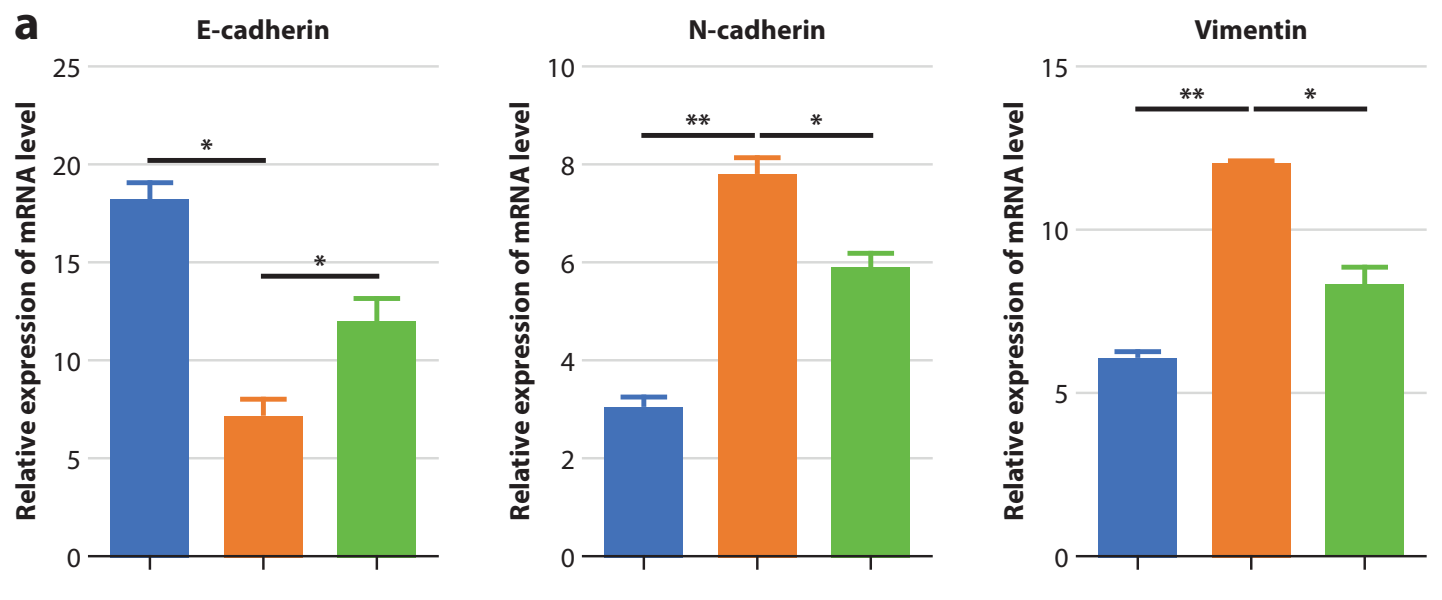

Control $\quad$ TGF- $\beta 1 \quad$ TGF- $\beta 1+$ miR-182 inhibitor

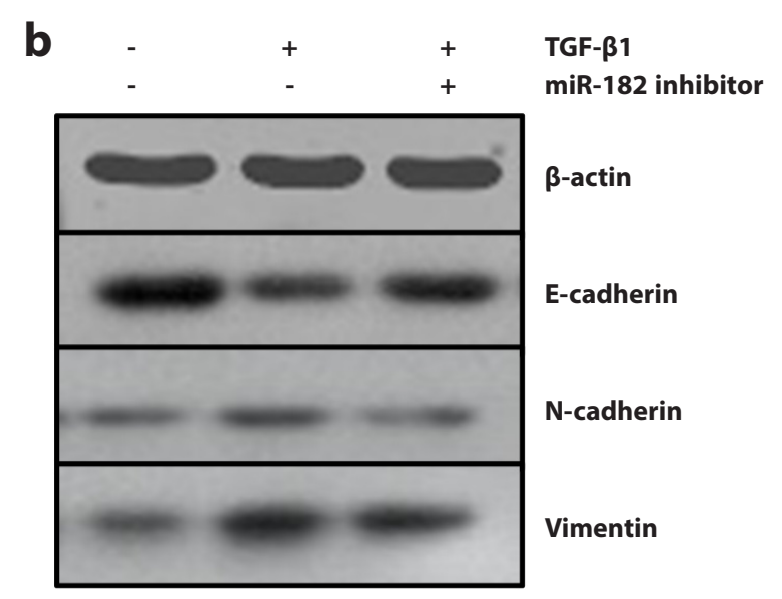

C
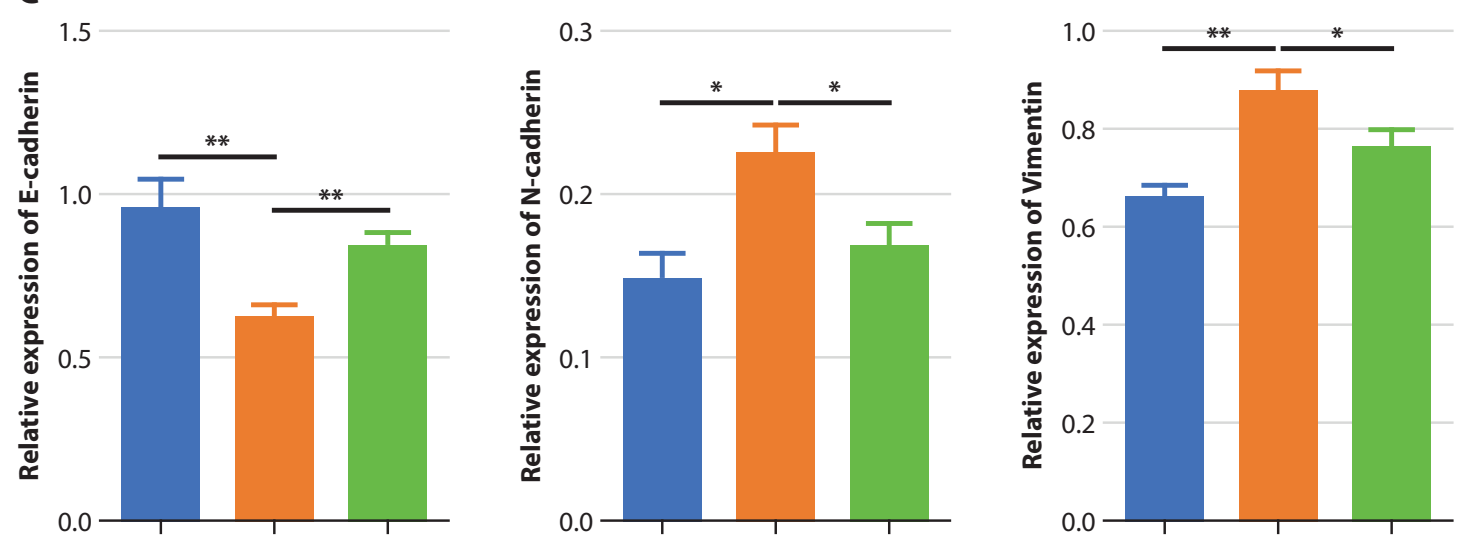

Control

TGF- $\beta 1$

TGF- $\beta 1+$ miR-182 inhibitor

Figure 6. miR-182 inhibitor inhibited TGF- $\beta 1$-induced EMT in hNEPCs

(a) The mRNA expression levels miR-182, E-cadherin, N-cadherin and vimentin in hNEPCs were assessed by qPCR. (b) The protein expression levels of E-cadherin, N-cadherin and vimentin in hNEPCs were detected by western blotting. (c) Quantitative analysis of E-cadherin, $\mathrm{N}$-cadherin and vimentin protein levels in hNEPCs

${ }^{\star} P<0.05,{ }^{* *} P<0.01$ 


\section{Discussion}

The pathophysiological mechanisms underlying the different subtypes of CRSwNP are largely unknown. In this study, we identified that miR-182 promotes EMT in hNEPCs in response to TGF- $\beta 1$ and therefore may play a potential role in tissue remodeling of patients with CRSwNP. To our knowledge, this is the first study to demonstrate the miR-182 regulatory networks associated with TGF- $\beta 1$ related to the EMT in Eos CRSwNP and non-Eos CRSwNP patients compared with control subjects. It is possible that further investigation and better understanding of the miRNAs in Eos CRSwNP and non-Eos CRSwNP may provide potential targets for therapeutic interventions in the future.

CRSwNP is a heterogeneous and multifactorial inflammatory disease of the paranasal sinuses and nasal cavities. ${ }^{1}$ CRSwNP results in a substantial burden with a prevalence of approximately $0.5 \%$ to $4 \%$ worldwide. ${ }^{1,22}$ Typical histological features of nasal polyps are dense inflammatory infiltrates, loose fibrous connective tissue with substantial tissue edema and a thickened basement membrane covered mostly by respiratory pseudostratified epithelium. ${ }^{2,23}$ Eosinophilic inflammation has been considered as a major pathologic hallmark of CRSwNP. ${ }^{21,22}$ Compared with non-Eos CRSwNP, Eos CRSwNP represents a hard-to-treat subtype of CRS and demonstrates a higher degree of disease severity and a worse response to surgery. ${ }^{24}$ Although Eos CRSwNP is characterized by Th2-biased cytokine profiles and non-Eos CRSwNP by predominantly Th1/Th17-biased patterns, ${ }^{25}$ the genes relating to the pathogenesis of different subtypes of CRSwNP are largely unknown.

Tissue remodeling is a typical response to chronic inflammation and provokes alterations in the structural organization of tissues, and EMT is a crucial mechanism involved in tissue remodeling. ${ }^{26} \mathrm{EMT}$ is a process in which epithelial cells lose polarity, junctional proteins are downregulated, the cytoskeleton becomes reorganized, and mesenchymal cell phenotypes are obtained. ${ }^{6}$ Accumulating evidence has confirmed that ongoing EMT leads to loss of epithelial barrier function, which would also contribute to disease progression, especially in CRSwNP. ${ }^{27}$ EMT is induced in the sinonasal epithelial cells by various allergens, pathogens, and pollutants. Besides, loss of the epithelial adhesion molecule, E-cadherin, is a typical finding during EMT; this phenomenon has been observed in CRSwNP tissues. ${ }^{28}$ Upon injury, epithelial cells undergoing EMT usually downregulate junctional proteins (such as E-cadherin) whilst modulating their cytoskeletal organization and acquiring mesenchymal features such as $\mathrm{N}$-cadherin and vimentin, which results in morphological changes. ${ }^{8,29}$ In agreement with previous reports, our study shows that E-cadherin expression was downregulated, but $\mathrm{N}$-cadherin and vimentin, expression was upregulated in nasal polyps from patients with Eos-CRSwNP and non-Eos CRSwNP and inferior turbinate from controls.

MiRNAs are a class $s$ of small noncoding RNAs that negatively regulate gene expression by inducing translational inhibition or transcript degradation. ${ }^{30}$ The recent insights into the roles of miRs have shown that noncoding miR can regulate the EMT process in airway epithelial cells. ${ }^{11}$ The miR-200 family miRNAs significantly increased E-cadherin expression and altered cell morphology to an epithelial phenotype. ${ }^{31}$
In CRSwNP patients, the expression levels of miR-21 and TGF- $\beta 1$ mRNA were increased compared with CRSsNP patients and control. ${ }^{32}$ miR-182 upregulation and TGF- $\beta 1$ overexpression accelerate EMT and promote cell migration and invasion in gallbladder cancer. ${ }^{18}$ Furthermore, miR-182 expression is upregulated in colorectal cancer, which significantly promotes epithelial-mesenchymal transition (EMT), cell proliferation, invasion and migration by targeting Special ATrich Sequence-Binding protein. ${ }^{19}$ Further observation showed that miR-182 suppressed the EMT via targeting Met and attenuating HGF/Met/Snail signaling in lung cancer. ${ }^{33}$

TGF- $\beta 1$ is a well-known stimulator of EMT, which induces the transition of epithelial cells into myofibroblasts, contributing to tissue remodeling and the pathogenesis of CRSwNP. ${ }^{17}$ Both upper and lower airway diseases have similar histopathologic features such as fibrosis, tissue remodeling, and extracellular matrix production, and those are associated with TGF- $\beta 1$ expression in the airway tissue. ${ }^{34}$ We checked the expression level of TGF- $\beta 1$ and miR182 in the sinonasal mucosal tissues from Eos CRSwNP, non-Eos CRSwNP and controls. Our tissue experiments showed that mRNA and protein expression of TGF- $\beta 1$ and miR-182 was strongly increased in both Eos CRSwNP and non-Eos CRSwNP. Based on these findings, we used an hNEPCs model, TGF- $\beta 1$ upregulates miR-182 expression and induces EMT transition of hNEPCs, which is reversed by miR-182 inhibitors. We acknowledge that there are still some potential limitations in this study. First, the number of our experimental specimens being quite limited may lead to bias of results and conclusion; Second, our experiment has not been verified by in vivo animal experiments, and systemic allergic factors cannot be excluded from the experiment.

\section{Conclusion}

In summary, our findings suggest the EMT transition occurs in both non-Eos CRSwNP and Eos CRSwNP. We have also revealed that the expression levels of miR-182 and TGF- $\beta 1$ were increased in both Eos CRSwNP and non-Eos CRSwNP, indicating that miR-182 and TGF- $\beta 1$ may play a significant role in the formation of EMT. Furthermore, we also found miR-182 causes mucosal EMT in hNEPCs in response to TGF- $\beta 1$, which can be reversed by adding miR-182 inhibitor. Therefore, TGF- $\beta 1$-mediated miR-182 production may be critical in tissue remodeling of patients with CRSwNP.

\section{Acknowledgments}

The authors thank the patients and their families. We thank all the members of the Department of Otolaryngology, Eye \& ENT Hospital, Fudan University, for their invaluable help.

\section{Statement of Ethics}

This study was approved by the ethics committee boards at the Department of Otolaryngology, Eye and Ear, Nose, and Throat Hospital, Fudan University. All study participants were enrolled after providing written informed consent. 


\section{Conflict of Interest Statement}

The authors have no conflicts of interest to declare.

\section{Funding Sources}

This work was supported by National Natural Science Foundation of China grant 81725004 and 81870703.

\section{Author Contributions}

- H.L. and G.H. mainly designed the study and revision of the manuscript.

- W.J. performed the survey, collected the data, performed the statistical analysis and drafted the manuscript.

- C.Z., C.M., and Y.C. mainly participated in parts of experimental procedures.

\section{References}

1. Fokkens WJ, Lund VJ, Hopkins C, Hellings PW, Kern R, Reitsma S, et al. European Position Paper on Rhinosinusitis and Nasal Polyps 2020. Rhinology. 2020;58

2. Meltzer EO, Hamilos DL, Hadley JA, Lanza DC, Marple BF, Nicklas RA, et al. Rhinosinusitis: establishing definitions for clinical research and patient care. The Journal of allergy and clinical immunology. 2004;114 (6 Suppl):155-212.

3. Hamilos DL. Chronic rhinosinusitis: epidemiology and medical management. J Allergy Clin Immunol. 2011;128(4):693-707.

4. Hulse KE, Stevens WW, Tan BK, Schleimer RP. Pathogenesis of nasal polyposis. Clin Exp Allergy. 2015;45(2):328-46.

5. Cao PP, Li HB, Wang BF, Wang SB, You XJ, Cui YH, et al. Distinct immunopathologic characteristics of various types of chronic rhinosinusitis in adult Chinese. J Allergy Clin Immunol. 2009;124(3): 478-84.

6. Kalluri R, Neilson EG. Epithelial-mesenchymal transition and its implications for fibrosis. J Clin Invest. 2003;112(12):1776-84.

7. Konnecke M, Burmeister M, Pries R, Boscke R, Bruchhage KL, Ungefroren $\mathrm{H}$, et al. Epithelial-Mesenchymal Transition in Chronic Rhinosinusitis: Differences Revealed Between Epithelial Cells from Nasal Polyps and Inferior Turbinates. Arch Immunol Ther Exp (Warsz). 2017;65(2):157-73.

8. Hupin C, Gohy S, Bouzin C, Lecocq M, Polette M, Pilette C. Features of mesenchymal transition in the airway epithelium from chronic rhinosinusitis. Allergy. 2014;69(11):1540-9.

9. Schleimer RP. Immunopathogenesis of Chronic Rhinosinusitis and Nasal Polyposis. Annu Rev Pathol. 2017;12:331-57.

10. Lee JM, Dedhar S, Kalluri R, Thompson EW. The epithelial-mesenchymal transition: new insights in signaling, development, and disease. J Cell Biol. 2006;172(7):973-81

11. Lamouille S, Xu J, Derynck R. Molecular mechanisms of epithelial -mesenchymal transition. Nat Rev Mol Cell Biol. 2014;15(3):178-96.

12. Mahmood MQ, Reid D, Ward C, Muller HK, Knight DA, Sohal SS, et al. Transforming growth factor (TGF) betal and Smad signalling pathways: A likely key to EMT-associated COPD pathogenesis. Respirology. 2017;22(1):133-40.

13. Shin HW, Cho K, Kim DW, Han DH, Khalmuratova R, Kim SW, et al. Hypoxia-inducible factor 1 mediates nasal polypogenesis by inducing epithelial-to-mesenchymal transition. Am J Respir Crit Care Med. 2012; 185(9):944-54.

14. Hackett TL, Warner SM, Stefanowicz D, Shaheen F, Pechkovsky DV, Murray LA, et al. Induction of epithelial-mesenchymal transition in primary airway epithelial cells from patients with asthma by transforming growth factor-beta1. Am J Respir Crit Care Med. 2009;180(2):122-33.
15. Li H, Liu Q, Wang H, Sun XC, Yu HP, Hu L, et al. Epithelialmesenchymal transition in chronic rhinosinusitis (CRS) and the prognostic value of alphaSMA in postoperative outcomes of patients with CRS. Mol Med Rep. 2019;20(3):2441-9.

16. Lu TX, Rothenberg ME. Diagnostic, functional, and therapeutic roles of microRNA in allergic diseases. J Allergy Clin Immunol. 2013;132(1):3-13.

17. Qing X, Zhang Y, Peng Y, He G, Liu A, Liu H. Mir-142-3p Regulates Inflammatory Response by Contributing to Increased TNF-alpha in Chronic Rhinosinusitis With Nasal Polyposis. Ear Nose Throat J. 2021; 100(1):NP50-NP6.

18. Zhang J, Hu Z, Wen C, Liao Q, He B, Peng J, et al. MicroRNA-182 promotes epithelial-mesenchymal transition by targeting FOXN3 in gallbladder cancer. Oncol Lett. 2021;21(3):200.

19. Yang MH, Yu J, Jiang DM, Li WL, Wang S, Ding YQ. microRNA-182 targets special AT-rich sequence-binding protein 2 to promote colorectal cancer proliferation and metastasis. J Transl Med. 2014;12:109.

20. Zhang A, Jin Y. MicroRNA-182-5p relieves murine allergic rhinitis via TLR4/NF-kappaB pathway. Open Med (Wars). 2020;15(1):1202-12.

21. Chen K, Yu Z, Yang J, Li H. Expression of cysteinyl leukotriene receptor GPR17 in eosinophilic and non-eosinophilic chronic rhinosinusitis with nasal polyps. Asian Pac J Allergy Immunol. 2018;36(2):93-100.

22. Rudmik L, Schlosser RJ, Smith TL, Soler ZM. Impact of topical nasal steroid therapy on symptoms of nasal polyposis: a meta-analysis. Laryngoscope. 2012;122(7):1431-7.

23. Van Bruaene N, Perez-Novo CA, Basinski TM, Van Zele T, Holtappels G De Ruyck N, et al. T-cell regulation in chronic paranasal sinus disease. J Allergy Clin Immunol. 2008;121(6):1435-41.

24. Zhang Y, Gevaert E, Lou H, Wang X, Zhang L, Bachert C, et al. Chronic rhinosinusitis in Asia. J Allergy Clin Immunol. 2017;140(5):1230-9.

25. Wang X, Zhang N, Bo M, Holtappels G, Zheng M, Lou H, et al Diversity of TH cytokine profiles in patients with chronic rhinosinusitis: A multicenter study in Europe, Asia, and Oceania. J Allergy Clin Immunol. 2016;138(5):1344-53.

26. Thiery JP, Acloque H, Huang RY, Nieto MA. Epithelial-mesenchymal transitions in development and disease. Cell. 2009;139(5):871-90.

27. Ryu G, Mo JH, Shin HW. Epithelial-to-mesenchymal transition in neutrophilic chronic rhinosinusitis. Curr Opin Allergy Clin Immunol. 2021;21(1):30-7.

28. Li X, Li C, Zhu G, Yuan W, Xiao ZA. TGF-betal Induces Epithelia -Mesenchymal Transition of Chronic Sinusitis with Nasal Polyps through MicroRNA-21. Int Arch Allergy Immunol. 2019;179(4):304-19.

29. Kalluri R, Weinberg RA. The basics of epithelial-mesenchymal transition. J Clin Invest. 2009;119(6):1420-8.

30. Liu ZL, Wang H, Liu J, Wang ZX. MicroRNA-21 (miR-21) expression promotes growth, metastasis, and chemo- or radioresistance in non-small cell lung cancer cells by targeting PTEN. Mol Cell Biochem. 2013;372 (1-2):35-45.

31. Korpal M, Lee ES, Hu G, Kang Y. The miR-200 family inhibits epithelial -mesenchymal transition and cancer cell migration by direct targeting of E-cadherin transcriptional repressors ZEB1 and ZEB2. J Biol Chem. 2008;283(22):14910-4.

32. Liu G, Friggeri A, Yang Y, Milosevic J, Ding Q, Thannickal VJ, et al. miR-21 mediates fibrogenic activation of pulmonary fibroblasts and lung fibrosis. J Exp Med. 2010;207(8):1589-97.

33. Li Y, Zhang H, Li Y, Zhao C, Fan Y, Liu J, et al. MiR-182 inhibits the epithelial to mesenchymal transition and metastasis of lung cancer cells by targeting the Met gene. Mol Carcinog. 2018;57(1):125-36.

34. Ojiaku CA, Yoo EJ, Panettieri RA, Jr. Transforming Growth Factor beta1 Function in Airway Remodeling and Hyperresponsiveness. The Missing Link? Am J Respir Cell Mol Biol. 2017;56(4):432-42. 